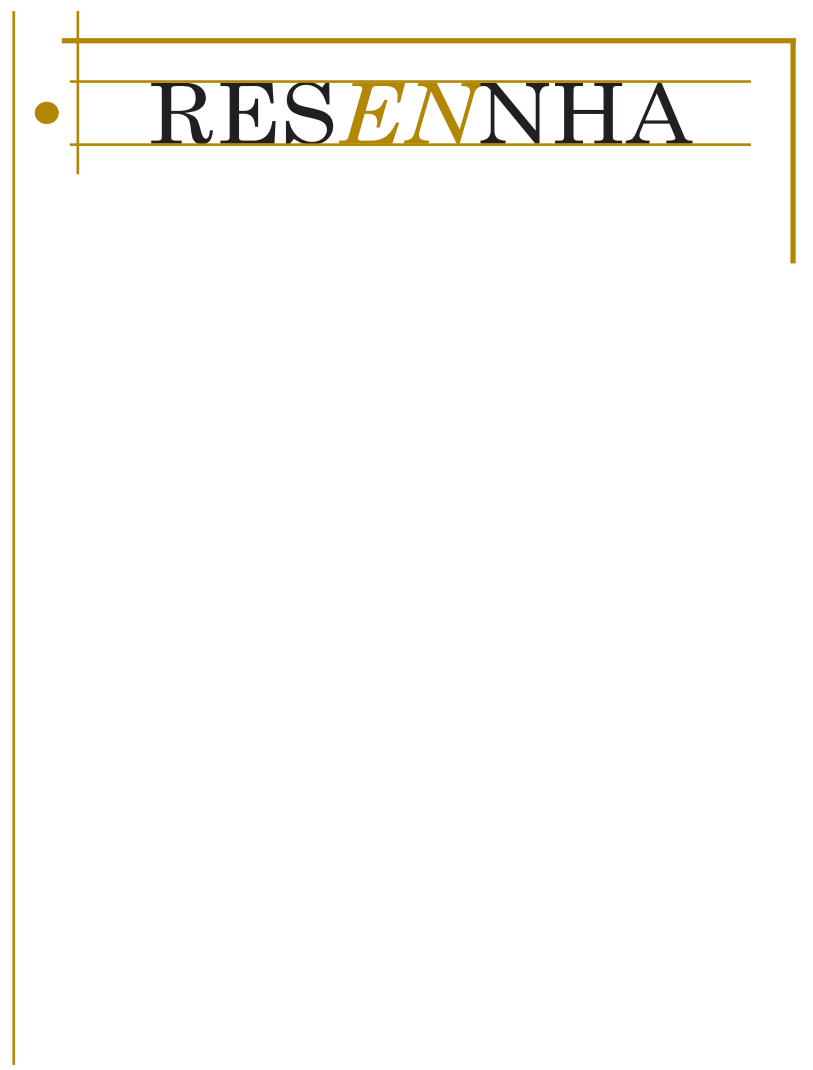




\section{LOS DICTADORES DE AYER - O SENHOR PRESIDENTE}

Graciela Foglia*

Miguel Ángel Asturias. Tradução Luis Reyes Gil.

São Paulo: Editora Mundaréu, 2016, 360 p.

Primero mataremos a todos los subversivos, luego mataremos a sus colaboradores, después a sus simpatizantes, enseguida a aquellos que permanecen indiferentes $y$, finalmente, mataremos a los tímidos. ${ }^{1}$

"E n tiempos sombríos, llenos de desconocimiento de la historia reciente de Brasil y del continente americano, cuando algunos piden que vuelvan las dictaduras o aplauden a torturadores y otros igualan a Augusto Pinochet y Fidel Castro, volver a publicar El señor Presidente, en portugués, nos da la oportunidad de repensar las "dictaduras" y los "dictadores" que forman parte de la historia de los siglos XIX y XX en nuestro continente y la literatura que los representa. La primera edición en portugués de la novela es de 1967, traducida por la novelista brasileña Antonieta Dias de Moraes, colaboradora de Casa de las Américas, con una introducción de Otto Maria Carpeaux. Esta nueva edición ${ }^{2}$ (2016) trae, además de una Introducción de la propia editorial Mundaréu, la traducción de un artículo clásico del intelectual venezolano Arturo Uslar Pietri y varias notas aclaratorias, al pie de página, del traductor.

El señor Presidente (1946) de Miguel Ángel Asturias (Guatemala, 1899-1974), ganador del Premio Lenin de la Paz (1965) y del Premio Nobel de Literatura

Universidade Federal de São Paulo (Unifesp) - Guarulhos - SP - Brasil. E-mail: graciela.fo@gmail.com

1 Afirmaciones del gobernador de la Provincia de Buenos Aires, Argentina, Ibérico Manuel Saint Jean, durante la última dictadura militar (1976-1983). Disponible en: <http://www.pagina12.com.ar/diario/ultimas/20-205033-2012-10-06.html>. Acceso 9 de dic. 2016.

2 ASTURIAS, M. A. O senhor presidente. São Paulo: Mundaréu, 2016. 
(1967), presenta un hecho que se reitera en la historia de América Latina desde los procesos de independencia, en el siglo XIX: las dictaduras. La novela cuenta dos historias: una de conspiración política, de arbitrariedades y asesinatos; otra, frecuente en la tradición romántica del siglo XIX, de amores frustrados. Ambas se desarrollan en el contexto de la dictadura de Manuel Estrada Cabrera, que gobernó Guatemala entre 1898 y 1920. Según el crítico uruguayo Ángel Rama ${ }^{3}$, algunas novelas, como la de Asturias, hablan de dictaduras:

[...] más o menos paternalistas, de los hacendados elevados a la primera magistratura y que durante decenios rigieron sus países como lo hacían con sus vastas haciendas, o de los militares que intentaban trasladar la conformación del cuartel a las formas de la convivencia social, o incluso de aquellos raros profesionales imbuidos de mesiánica e ilustrada fe en que habían sido ungidos como protectores, guías y únicos intérpretes de la voluntad popular. (RAMA, 1976, p. 5).

Además, El señor Presidente es el antecedente de otras novelas sobre caudillos y dictadores del siglo XIX y principios del XX, que serian publicadas en los años 1970. Las más conocidas son El recurso del método (1974) de Alejo Carpentier, Yo, el supremo (1974) de Augusto Roa Bastos y El otoño del patriarca (1975) de Gabriel García Márquez. Novelas estas que se suman, según Rama, a una "larga tarea intelectual [que desarrollaron] los historiadores revisionistas del Río de la Plata para desmontar la concepción oligárquica de la historia" (1976, p. 13) que se impuso desde las independencias, concepción que ayudó a moldar las identidades hispanoamericanas. No es exactamente el caso de El señor Presidente, que todavía conserva algo de la mirada liberal ${ }^{4}$ de los letrados del siglo XIX, bastante diferente de lo que después Carpentier, García Márquez o Roa Bastos harian en sus "novelas de dictador". Sin embargo, en la época de la primera publicación en Brasil, 1974, Otto Maria Carpeaux leía la novela como politica y revolucionaria por haber reconciliado las vanguardias literarias y social, "a revolução literária e a revolução política"5 (CARPEAUX, 1974, p. 14), muy diferente de lo que, de hecho, haría el pensamiento liberal.

El señor Presidente, escrita entre 1922 y 1931, después de la caída de la dictadura de Estrada Cabrera, pero publicada en 1946, es la primera novela del autor y la más conocida. En esta todavía no aborda, de la forma que lo haría después, la temática maya ni los mitos y leyendas que aparecerán en Leyendas de Guatemala (1930), Hombres de maí (1949) o Mulata de tal (1963) ${ }^{6}$.

Miguel Ángel Asturias, novelista, poeta, periodista, diplomático; comprometido con la realidad de su país, estuvo exiliado y fue despojado de su ciudadanía durante uno de los tantos gobiernos de facto que hubo en Guatemala. También fue una figura polémica, bastante cuestionado por los intelectuales de izquierda en los años sesenta debido a su colaboración con algunos de aquellos gobiernos ${ }^{7}$.

\footnotetext{
RAMA, A. Los dictadores latinoamericanos. México: Fondo de Cultura Económica, 1976.

En el sentido de defender la libertad, en contra del conservadurismo, pero también defendiendo los valores de la burguesía.

CARPEAUX, O. M. O romance como poema e a ditadura como realidade. O senhor presidente. São Paulo: Brasiliense, 1974

MARTIN, G. Introducción del coordinador. Miguel Ángel Asturias. El señor Presidente. Edición crítica, Gerald Martín, coordinador. Madrid: ALLCA XX, 2000. (Colección Archivos).

7 Ver MONEGAL, E. R. Los dos Asturias. Revista Iberoamericana [en línea]. Disponible en <http://revistaiberoamericana.pitt.edu/ojs/ index.php/lberoamericana/article/viewFile/2330/2523>. Acceso 26 jun. 2014; ROSADO, J. A. Miguel Ángel Asturias: vocero de su tribu. Disponible en: <http://www.revistadelauniversidad.unam.mx/ojs_rum/index.php/rum/article/view/14892/16130>. Acceso 12 abr. 2016.
} 
A pesar de esas colaboraciones de Asturias, que deberian ser comprendidas en su contexto, El señor Presidente es, como dice el crítico uruguayo Jorge Ruffinelli, " "un libro 'comprometido', esto es, una denuncia de la dictadura como un sistema de terror, de violencia y tortura" (2000, p. 873); y Ángel Rama reconoce que esta novela de Asturias junto con El gran Burundún-Burundá ha muerto de Jorge Zalamea son las primeras tímidas y posibles formas de aproximación a la temática del dictador, "mucho más ricas, más comprensivas de la realidad profunda, que los innumerables volúmenes de diatribas contra las dictaduras [...] que han pululado en el continente" (1976, p. 10). "Tímidas y posibles" porque, para la época de la redacción de esas novelas, algunos intelectuales de América Latina estaban empezando a entender el significado de lo que José Martí había señalado en el siglo XIX, en el ensayo "Nuestra América": mientras Europa no dejase de ser el modelo interpretativo de nuestras sociedades, mientras no se profundizase sobre la vida de los pueblos latinoamericanos desde una perspectiva que no fuese la de los libros europeos y la de las formas de sociabilidad de aquel continente, nuestra realidad continuaria siendo incomprendida (2006, p. 196).

Por eso, porque se trata de una de las primeras y tímidas aproximaciones a la temática del dictador desde un punto de vista que intenta ser diferente del de los letrados del siglo XIX, pero que todavía está marcado por la formación liberal del autor, junto con la denuncia de la violencia dictatorial, el texto tiene características de esa formación ya sea en lo que se refiere a la representación del amor romántico (Ruffinelli, 2000, p. 872) o en pasajes, que Ruffinelli llama "traiciones textuales", que se refieren a pobres, indigenas o prostitutas. A modo de ejemplo, véase el siguiente trecho en relación a los mendigos: "Nunca se supo que se socorrieran entre ellos; avaros de sus desperdicios, como todo mendigo, preferian darlos a los perros antes que a sus compañeros de infortunio"10 (cursiva mía). Ruffinelli dice también que "la dictadura, tal como la expone Asturias [...], parece el instrumento de un individuo y de su guardia personal; nada hay fuera de eso, ni una institución llamada ejército [...] ni una coherente y sólida actitud de la empresa privada" (2000, p. 881), como si las dictaduras no se mantuviesen con la complicidad de intereses económicos y de poder.

Sin embargo, tal vez, las dictaduras que vivenció Asturias no tenían la falta de pudor y la impunidad que permiten declaraciones como la del epígrafe. Cuando nuestros Estados empezaron a torturar y a matar en masa a sus ciudadanos, cuando planearon el exterminio sistemático de opositores y legitimaron los escuadrones de la muerte y sus asesinos y torturadores fueron "letrados" en la Escuela de las Américas, esa literatura cambió. Ya no se trata del paternalismo de los hacendados, ni de "protectores, guías y únicos intérpretes de la voluntad popular"; los "cómplices" ya no son los menos favorecidos; los cómplices (sin comillas) ahora son parte de la clase media, del empresariado, de los grupos económicos, de los medios de comunicación... Dice Alberto Moreiras ${ }^{11}$ (2001,

8 RUfFINELLI, J. Las 'traiciones' textuales de El señor Presidente. In: ASTURIAS, M. A. El señor Presidente. Ed. crítica, Gerald Martín, coord. Madrid: ALLCA XX, 2000.

9 MARTí, J. Nossa América. Trad. M. A. de Almeida Triber. São Paulo: Hucitec, 2006, p.196.

10 ASTURIAS M. A. El señor Presidente. Ed. crítica, Gerald Martín, coord. Madrid: ALLCA XX, 2000. p. 8. La cita se puede encontrar en la p. 28 de la edición brasileña (ASTURIAS, 2016).

11 MOREIRAS, A. A aura do testemunho. In: MOREIRAS, A. A exaustão da diferença: a política dos estudos culturais latino-americanos. Tradução Eliana Lourenço de Lima Reis e Gláucia Renate Gonçalves. Belo Horizonte: Editora UFMG, 2001. p. 249-282. 
p. 369, nota 4) que desde el comienzo y hasta mediados de los años ochenta hay un cierto agotamiento de la literatura (que el autor llama) del boom y del pós-boom junto con un movimiento de solidaridad y horror frente a la represión en Argentina y a las guerras civiles en América Central y las atrocidades cometidas por sus gobiernos, agotamiento que asegura una popularidad generalizada de la literatura de testimonio. Parece que ya no queda espacio para el Realismo Mágico de las novelas de dictador, ni para la atmósfera onírica de El señor Presidente.

Título em portugês: Os ditadores de ontem

Título em inglês: The dictators of yesterday

\section{REFERÊNCIAS}

CARPEAUX, O. M. O romance como poema e a ditadura como realidade. In: $O$ Senhor Presidente. São Paulo: Brasiliense, 1974.

ASTÚRIAS, M. Á. O Senhor Presidente. São Paulo: Mundaréu, 2016.

RAMA, A. Los dictadores latinoamericanos. México: Fondo de Cultura Económica, 1976.

Recebido em 09-12-2016.

Aprovado em 15-02-2017. 